\title{
TRAINING INDUCED SKIN INJURIES AND THEIR PROPHYLAXIS IN FITNESS COMPETITORS
}

\author{
N. Yankova*, V. Panayotov \\ National Sports Academy „Vasil Levski“, Weightlifting, Boxing, Fencing and Sport for All, \\ Sofia, Bulgaria
}

\begin{abstract}
PURPOSE. In many sports exists a potential risk of training-induced skin injuries with subsequent bleeding and possible inflammation. Athletes of contact sports are especially susceptible to virus skin infections. This research was aimed at studying the specifics of training-induced skin traumas in fitness athletes and their prophylaxis. METHODS. We applied the inquiry method and alternative analysis. Our questionnaire comprised 17 questions in total: 15 of them of closed type and 2 of open type. Additionally, before questioning our participants, we informed them about the purpose of our research and gave them instructions on how to fill the questionnaire. RESULTS. We found that the most common skin injuries in fitness trainees are located on the palms (corns) and the shanks (bruises without bleeding). Although in gymnasiums trainees have contact with different surfaces and this greatly increases the risk of spreading of different skin infections, only $3 \%$ of the participants have ever suffered mixed skin diseases.

CONCLUSIONS. Adhering to proper prophylaxis measures protocols can prevent most of the losses of training days and subsequent deterioration in performance caused by training-induced skin injuries that are often left untreated.
\end{abstract}

Key words: skin infections, shank bruises, palm corns, resistance training

\section{INTRODUCTION}

In many sports exists a potential risk of training-induced skin injuries with subsequent bleeding and possible inflammation. Athletes of contact sports are especially susceptible to virus skin infections. To prevent their spreading among trainees, these conditions should be adequately diagnosed and accurate prophylaxis measures should be taken by both athletes and gymnasiums' personnel (1-3). According to recent data, $56 \%$ of all conditions occurring in competitive athletes of all sports were skin diseases (4).

Trainees in fitness gymnasiums are at high risk of getting infected with skin diseases due to the direct hand contact on different machines and free weights they share during exercising. The same is true for many other sports that use

\footnotetext{
*Correspondence to: Nely Yankova National Sports Academy ,, Vasil Levski“, Weightlifting, boxing, fencing and sport for all, 1700, Sofia, Studentskigrad, E-mail: yankova_nsa@abv.bg, Mobile: 00359893396422
}

resistance training for strength development as a part of their periodization plans (i.e. judo, sports games, wrestling, etc.).

Skin injuries are common conditions in fitness training: the most common are corns, eczemas, non-bleeding bruises, and fungal infections. According to some authors, the causes of training-induced skin infections can be classified into two main groups (5-8).

- External: equipment malfunctions (including defects in free weights equipment); non-compliance of trainees to hygiene rules;

- Internal: inadequate physical or technical proficiency; lack of basic prevention skills for skin injuries.

Palm corns are a frequent condition in athletes engaged in resistance training. They are caused by the pressure that is induced between trainees' palms and bars and handles during exercise: it elicits thickening of the surface layers of the skin. Habitual strength training is 
associated with hard and big palm corns, especially in athletes with dry skin. Palm corns can be a big challenge to the training process as lower skin layers are more delicate can be easily damaged and inflamed. Such conditions can jeopardize the entire preparation process for long periods and frequently even impair competitive performance (9).

Eczemas are also common in fitness trainees. They can attack both the palms and wrists: on the palms they are located between the thumb and forefinger and are caused by the tight grips athletes use on bars and handles; on the wrists, they are caused by frequent straps usage. In gymnasium environments, eczemas can easily spread among many trainees that share the same training equipment - bars, dumbbells, machine handles, straps, etc.

As the bar surface is jagged, while pulling it close to the body during the deadlift (both during the first and the second lift) metal chips (although seldom) can wound the skin and cause inflammations. Generally, improper exercise technique can cause different skin injuries, including bruises and even superficial bleeding wounds. Bruises and wounds on the shanks and neck are common skin conditions in athletes that train with free weights. The rough bar surface can also cause bruises and hyperkeratinization by sliding along the neck and upper back during the back squat.

Fungal infections are frequently caused by trainees wearing sports shoes for long periods. Using socks of synthetic materials can further complicate the condition and facilitate the spread of the infection. In our opinion, classifying fitness training-related skin injuries and determining their causes can be used as a base for elaborating instructions and guidelines for minimizing their frequency and severeness.

\section{METHODS}

This research was aimed at studying the specifics of training-induced skin traumas in fitness athletes and their prophylaxis. To accomplish this aim, we set the following objectives:

1. To establish the main causes of traininginduced skin injuries.

2. To establish the number and type of training-induced skin injuries in fitness trainees.

3. To study the relationships between training-induced skin injuries and their prevention and prophylaxis in fitness trainees.

We applied the inquiry method and alternative analysis. Our questionnaire comprised 17 questions in total: 15 of them of closed type and 2 of open type. Additionally, before questioning our participants, we informed them about the purpose of our research and gave them instructions on how to fill the questionnaire. The subjects of this study were 36 male fitness competitors aged 27.8 4.5 years and training experience of $9 \pm 2.3$ years. The research was held between October 2018 and March 2019 in several fitness facilities in Sofia, Bulgaria.

\section{RESULTS}

All participants answered the question "How do you evaluate the hygiene conditions at the facility you exercise" with "Good". According to $58 \%$ of them, the gymnasiums they exercise have special personnel that is responsible for maintaining adequate hygiene conditions (the other $42 \%$ gave negative answers). $92 \%$ of our respondents stated that in cases of blood on a bar or a handle resulted from a skin injury, the staff usually clears the surface promptly. On the other hand, in $8 \%$ of such cases, no hygiene measures for preventing a potential spread of skin infections were taken whatsoever. According to our results, the most common locations of training-induced skin injuries are these on the palms $(75 \%$ of the cases), and on the shanks (25\% of the cases) (Figure 1).

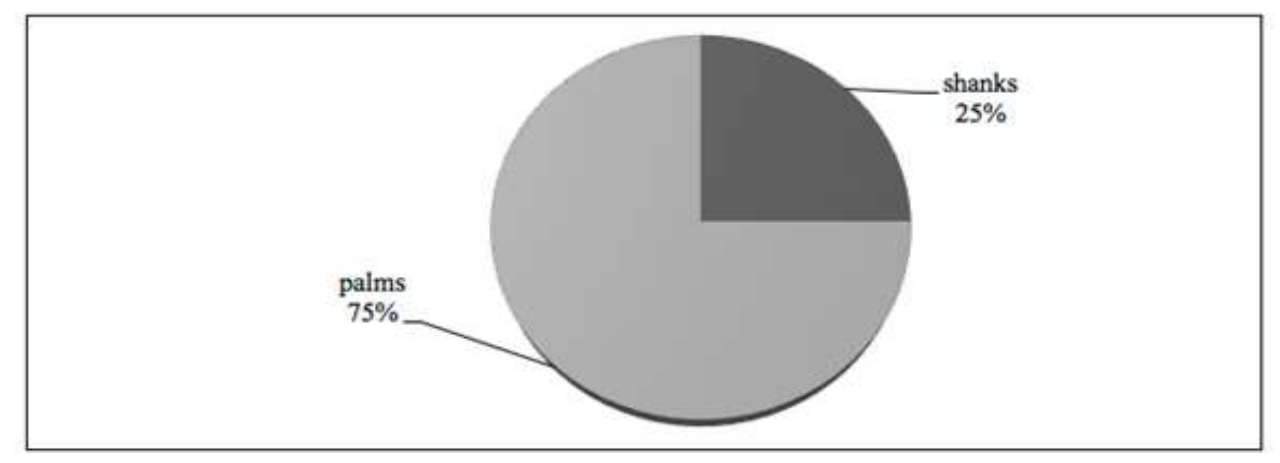

Figure 1. Distribution of fitness training-induced skin injuries by body area 
We found that the most common skin injuries in fitness trainees are located on the palms (corns) and the shanks (bruises without bleeding). Palm corns are caused by the roughness of bars and $75 \%$ of our respondents declare that they suffer or have suffered them. Shank bruises are relatively rarer $-25 \%$ of the interviewed athletes answered that they have a history of them. Shank bruises are caused by the bar when it accidentally rubs shank skin during the initial phases of the deadlift. Admittedly, these incidents do not look like serious traumas but they can often degenerate into skin erosions - a loss of some or all of the epidermis leaving a denuded surface. Shank bruises are caused by an improper exercise technique and can be easily avoided if coaches allocate enough training time to learning complex movements at the early stages of athletes' careers.

$67 \%$ of our subjects answered the question "Do you seek medical assistance for these skin injuries?" by "Never" and 33\% - by "Sometimes". Evidently, most athletes neglect the medical treatment of training-induced skin injuries and that, in our opinion, can potentially hinder the entire training process by causing infections and a consecutive loss of training hours.

Surprisingly, $92 \%$ of the respondents stated that they have never suffered training-induced
YANKOVA N. et al.

rashes or eczemas. $95 \%$ of the athletes that had histories of such conditions had either short training experiences or did not seek medical care timely. $100 \%$ of our respondents declare that they have never participated in competitions with co-competitors infected by skin conditions.

Although in gymnasiums trainees have contact with different surfaces and this greatly increases the risk of spreading of different skin infections, only $3 \%$ of the participants have ever suffered mixed skin diseases. In our opinion, the frequency of training-induced skin injuries depends to a much lesser degree on the number of simultaneously training athletes than on the average training intensity: the higher the intensity the greater the risk of skin injuries.

Regarding the usage of fitness accessories, $50 \%$ of the respondents declared they use mats, $35 \%$ - straps, $10 \%$ - gloves, and only 5\% belts (Figure 2). Fitness accessories are used for injury prevention but, as not every trainee can afford purchasing all of them, they are often subjected to a common use by many athletes, which increase the potential risk of spreading skin infections. $67 \%$ of the participants answer the question "Are you acquainted with skin diseases that can be spread by athletes that use common fitness accessories?" positively.

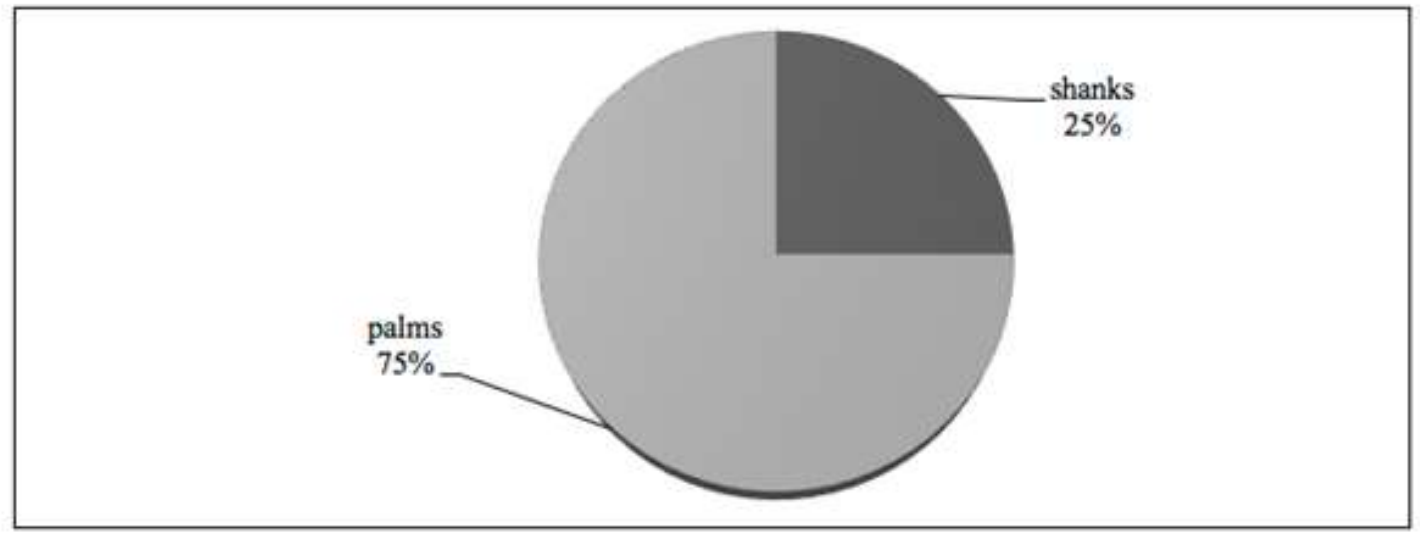

Figure 2. Most commonly used fitness accessories

$75 \%$ of the respondents think that fitness facilities' personnel act adequately in cases of skin injuries and successfully prevent or localizes the spread of infections. Furthermore, $67 \%$ of them consider as necessary special lectures and instructions to be given to trainees regarding the prophylaxis of fitness traininginduced skin injuries.

Three groups of measures for preventing skin infections spreading among fitness trainees were differentiated as the most important by our subjects: 
YANKOVA N. et al.

1. Regular cleaning of the fitness equipment with antibacterial substances.

2. Regular hand washing with antibacterial soaps.

3. Trainees to learn a proper exercise technique before they begin to train at high intensities.

The risk of training-induced skin injuries can be drastically reduced if coaches and trainees take some simple prophylaxis measures, among them: to perfect the exercise technique, to regularly clean bar's and handles' surfaces, and in case of a skin injury - to regularly treat the affected areas. Bleeding wounds should be promptly reported to coaches or medical staff to be taken care of. Training should be discontinued until the bleeding is stopped by bandaging the affected area. No exercises that can potentially worsen the condition and spread the infection should be performed.

Many authors emphasize the importance of early prophylaxis measures for preventing training-induced skin injuries but regrettably, they are frequently neglected by coaches and athletes $(5,7,8,10,11)$. A special attention in this regard should be paid to barbell bars. They should be perfectly straight and to roll freely in their bearings. Oftentimes, neglecting the abovementioned requirements is the main cause of bleeding bruises and the potential spreading of skin infections.

Additionally, trainees should regularly inspect their palm skin and not allow big and hard corns to form. Corns should be cautiously cut by special cosmetic rasps until the skin is levelled. Athletes should also prevent the formation of palm corns by regularly anointing their palm skin with urea containing creams before a workout: they should wait until the skin entirely absorbs the cream before they begin exercising (12).

In our opinion, coaches should guide trainees' attention to these elements of the exercise technique that bear the biggest risks of skin injuries. Frequently, at the early stages of fitness training, these details may seem insignificant but a wrong technique would most probably cause (sometimes) serious skin traumas later as training intensity increases with sports proficiency.

Simple hygiene measures can be quite effective in preventing the spreading of skin infections among training groups. Avoiding the sharing of common accessories is one of the most potent tools in this regard: our data show that many trainees share common mats and straps. These two pieces of equipment are especially "useful" vehicles for spreading infections as they are in direct contact with athletes' bodies and straps can be easily infected by the light wrist bruises they often cause. Common gloves and belts are less virulent agents as they are seldom shared between different athletes. Generally, for novice trainees, coaches should pay much attention to the prophylaxis of training-induced skin injuries. The same guidelines should be followed in strength training for sports as frequently these athletes are less experienced in performing complex resistance exercises.

\section{CONCLUSIONS}

Based on the analysis we derived the following conclusions:

1. Many fitness training-induced skin injuries are most probably caused by the neglecting of the prophylaxis measures and training on high intensities.

2. Training-induced skin injuries are one of the most frequent sports traumas in resistance training. Coaches should insist and control athletes to adhere to prophylaxis measures.

3. Adhering to proper prophylaxis measures protocols can prevent most of the losses of training days and subsequent deterioration in performance caused by training-induced skin injuries that are often left untreated.

\section{REFERENCES}

1. Zlatkov, N., Petranov, E., Terapia na kojnite i polovo predavani bolesti. ARSO, 2000.

2. Zlatkov, N., Dermatologia i seksualno predavani bolesti. ARSO, 1997.

3. Boucher, H. and Corey, G., Epidemiology of Methicillin-Resistant Staphylococcus aureus, Clin Infect Dis., 46 (Supplement 5): S344-S349, 2008.

4. Bracker, M., The 5-Minute Sports, Medicine Consult, 2011.

5. Vorobev, N., nekotorie fiziologicheskie i gigienicheskie osnovi tezhaloi atletiki. Tezzhalaia atletika. Moskva, Fizultura i sport, 1967.

6. Gurkov, D., Tezhka atletika $\mathrm{v}$ detska i unosheska vazrast. NSA, Sofia, 1992

7. Dagorov, N., Sportni travmi. Sofia, 2002. 
8. Dobrev, P., Gurkov, D., Spasov, A., Tezhka atletika, Sofia, 1976.

9. Adams, B., Dermatologic disorders of the athlete, Sports Med, 32(5):309-321, 2002.

10. Yankova, N., Slaavova, V., Panayotov, V., Valchev, V., Kojni naraniavania v trenirovacni uslovia i tianhnata prevencia vav vdiganeto na tevesti. Sbornik dokladi ot nauchna konferencia "Predizvikatelstva i perspektivi pred sportnata nauka", "Problemi pred savremennia sport", Sport i nauka, 1: 184-193, 2018.
YANKOVA N. et al.

11.Yankova, N., Slaavova, V., Panayotov, V., Valchev, V., Kapandjiev, I., Kojni naraniavania $\mathrm{v}$ trenirovacni uslovia $\mathrm{i}$ tianhnata prevencia v silovia triboi. Sbornik dokladi ot nauchna konferencia "Predizvikatelstva i perspektivi pred sportnata nauka", "Problemi pred savremennia sport”, Sport i nauka, 1: 194203, 2018.

12. Katsambas, A., Lotti, T., Dessinioti, C., D'Erme, A., European Handbook of Dermatological Treatments (3 ed.). Springer, 2015. 